Chenzhi Xia

Li Cheng

Can Luo

Weixuan Jiao

Di Zhang

https://doi.org/10.21278/TOF.42408

ISSN 1333-1124

eISSN 1849-1391

\title{
HYDRAULIC CHARACTERISTICS AND MEASUREMENT OF ROTATING STALL SUPPRESSION IN A WATERJET PROPULSION SYSTEM
}

\begin{abstract}
Summary
Rotating stall as a kind of ship stall causes noise, vibration and unstable operation of a waterjet propulsion system and sometimes it can even cause fracture of blades and destruction of other flow passage components. To investigate the suppression of the rotating stall, a complete 3-D waterjet propulsion system model has been developed which contains an inlet passage, a propulsion pump and a nozzle. Hydraulic performance and flow characteristics are predicted by using a numerical simulation, which is in good agreement with the experimental results. For suppressing the rotating stall, separators are set in the outlet of the inlet passage. The analysis has shown the following: the rotating stall zone is found to be significant on the external characteristic curve in the low flow rate condition. Also, in the same condition a large scale flow separation region occurs in the propulsion pump, which is more intense at the rim of the impeller. The rotating stall of the propulsion pump system is controlled by setting separators at the outlet of the inlet passage. The recommended parameters of the separators are $0.5 D_{0}$ (length), $0.1 D_{0}$ (height), $0.4 D_{0}$ (location), $0.025 D_{0}$ (thickness), 4 (number of separators), where $D_{0}$ presents the outlet diameter of the inlet passage.
\end{abstract}

Key words: $\quad$ water jet propulsion system; rotating stall; stall suppression.

\section{Introduction}

Unlike the propeller propulsion system, the water jet propulsion system ejects water from the propulsion pump, forming a reaction force and creating thrust [1]. The water jet propulsion system has been used in high performance vessels due to its advantages. However, there exists a problem that ship stall affects ship navigation seriously. The results show that there are two types of ship stall, including wind wave stall and rotating stall, which are caused by wave parameters, length of the ship, linear square coefficient of the hull, wind resistance on the hull and reduced propulsion efficiency [2]. The wind wave stall is related to the four factors mentioned first, while the rotating stall is mainly related to the last factor. Some scholars and experts pay more attention to wind wave stall [3-6] and rotating stall [7-12] rather than to a systematic analysis of rotating stall in the propulsion pump. In this paper, 
causes of the rotating stall in the propulsion pump are analyzed and beneficial suppression measures are presented.

\section{Numerical setup}

\subsection{Numerical model}

Figure 1 shows the entire computational model of a waterjet propulsion system, which includes an inlet passage, a propulsion pump (mixed-flow pump) [13] and a nozzle. The propulsion pump consists of an impeller with six blades and a guide vane with seven vanes. The rotational speed of the impeller is $700 \mathrm{r} / \mathrm{min}$. The inlet passage consists of an inlet, an outlet, a lip and a transition section. $D_{0}$ presents the outlet diameter of the inlet passage. $\theta$ presents the dip angle of the inlet passage. Considering the influence of navigation speed on the performance of a waterjet propulsion system, the computational domain contains a water body at the bottom, as shown in Fig. 1.

The inflow velocity boundary condition is applied to the inlet boundary of the water body, which equals navigation speed. Nominal turbulence intensity (with a value equal to 5\%) is used at the inlet boundary. Pressure outlet is used at the outflow boundary of the water body (with a pressure equal to $105.8 \mathrm{kPa}$ ) and the mass flow rate is specified at the outlet boundary of the nozzle. The impeller rotating speed is $700 \mathrm{r} / \mathrm{min}$ and the interface between the impeller and the guide vane is set as Frozen Rotor. The flow through the waterjet propulsion system is simulated with the commercial code ANSYS CFX 13.0, which uses the finite volume method to solve Reynolds averaged Navier-Stokes equations for incompressible steady flow. The standard $k-\varepsilon$ model is used to complement the flow model. The first order upwind schemes are applied. The convergence precision is set to $10^{-5}$.

\subsection{Grid division and sensitivity analysis}

The entire computational domain is generated with a hexahedral structured grid by using the ICEM software. The precision of the simulation results would be improved gradually with an increase in the grid number. However, the use of higher resolution grids results in an increase in the demand for computing resources, which are limited. So, in this study, six kinds of grid number ranging from $4.3 \times 10^{5}$ to $2.1 \times 10^{6}$ are used to simulate the reduction of the influence of the grid number on computation and to save computing time. In this paper, the range of the $\mathrm{y}^{+}$value of the propulsion pump is $30-100$.

Table 1 presents an analysis of grid sensitivity. The head of the propulsion pump is calculated by using Eq. (2) and the efficiency is obtained from Eq. (4), Section 3. The predicted result shows that the head and efficiency of the pumping system fluctuate with an increase in the number of grid elements. When the number reaches $1.5 \times 10^{6}$, the fluctuating value is relatively small, which indicates stable simulation. Hence, grid elements of the entire computational domain are selected as 1752299 for the following investigation. Fig. 2 shows meshes of the pumping system, including nozzle, guide vane, impeller and inlet passage.

Table 1 Grid sensitivity analysis of propulsion pump

\begin{tabular}{ccc}
\hline Grid elements & Head $H / \mathrm{m}$ & Efficiency $\eta / \%$ \\
\hline 432586 & 0.726 & 0.401 \\
721586 & 0.741 & 0.412 \\
1216872 & 0.784 & 0.450 \\
1460247 & 0.801 & 0.466 \\
1752299 & 0.805 & 0.468 \\
2102758 & 0.799 & 0.466 \\
\hline
\end{tabular}




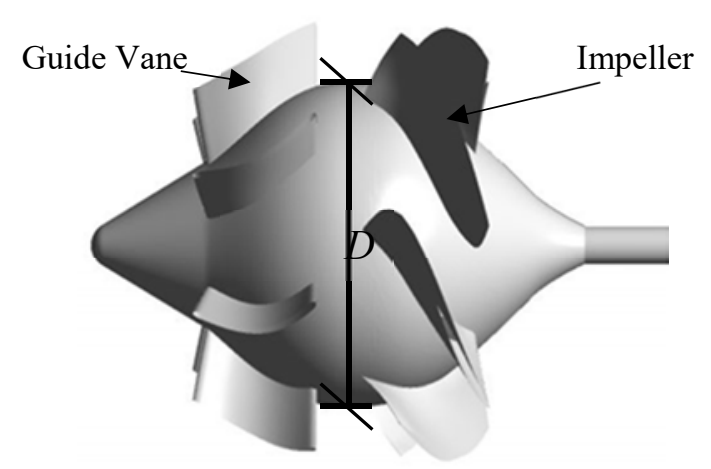

(a) Propulsion pump

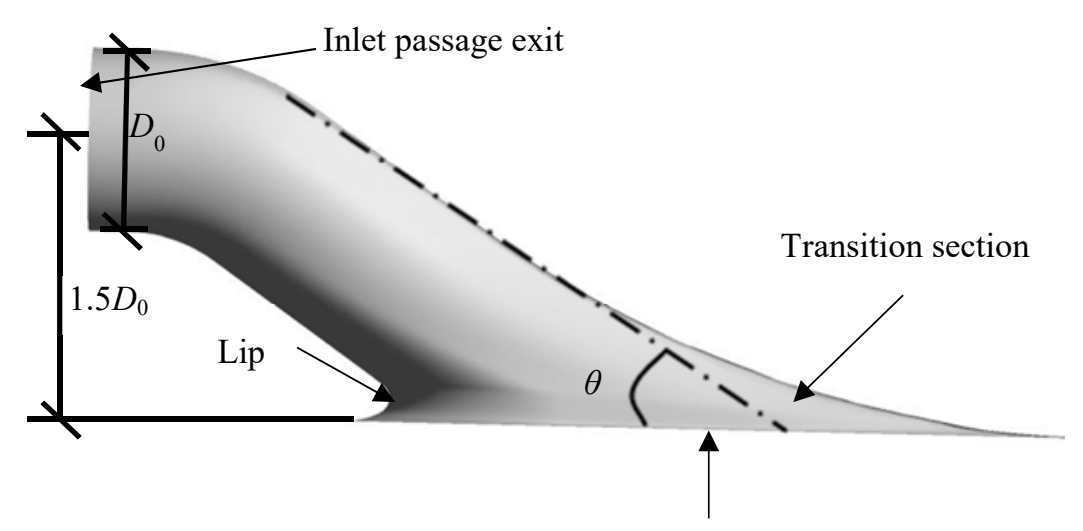

Inlet passage entrance

(b) Inlet passage

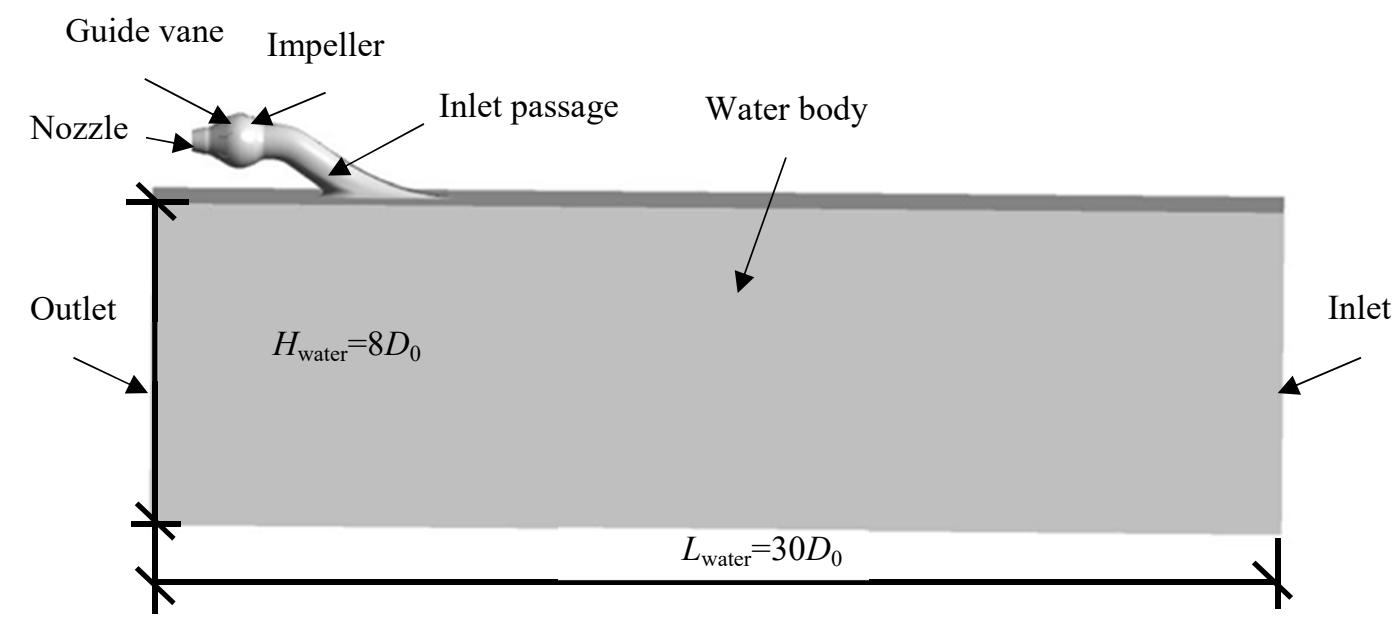

(c) Computational domain

Fig. 1 Computational domain of waterjet propulsion pumping system 
C. Xia, L. Cheng, C. Luo, W. Jiao, D. Zhang

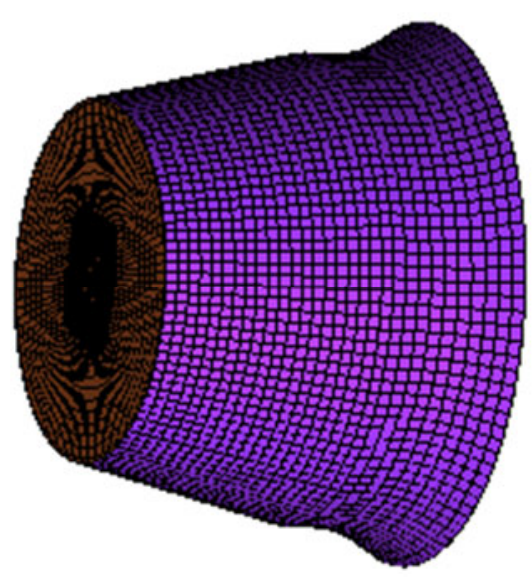

(a) Nozzle

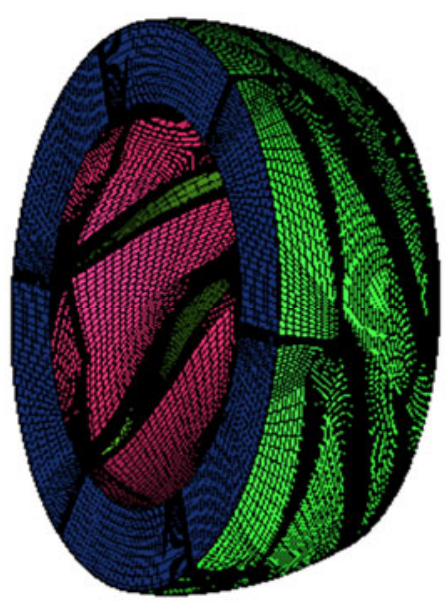

(c) Impeller
Hydraulic Characteristics and Measurement of Rotating Stall Suppression in a Waterjet Propulsion System

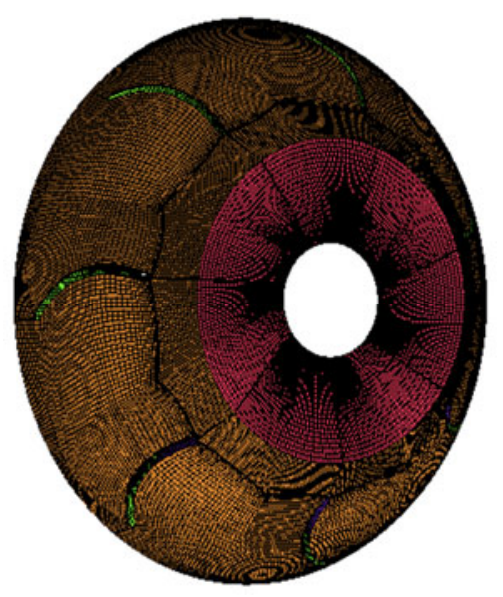

(b) Guide vane

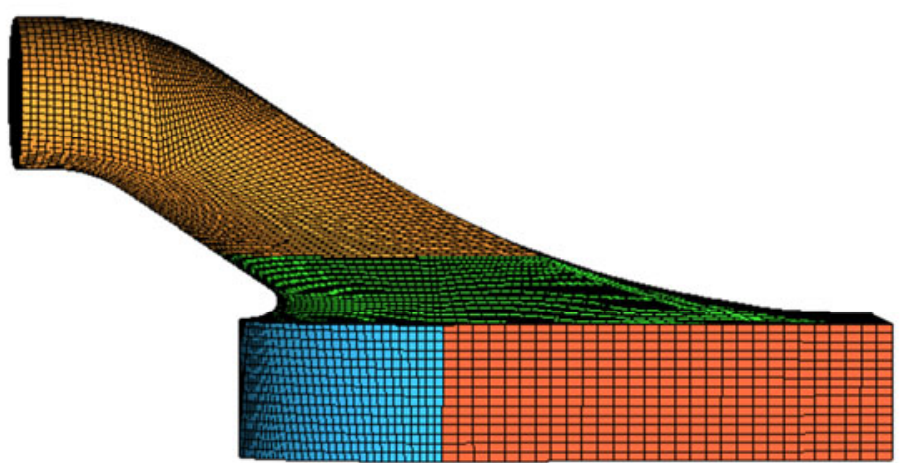

(d) Inlet passage grid

Fig. 2 Meshes of every part of water jet propulsion system

\section{Hydraulic performance}

In order to calculate the hydraulic performance of the propulsion pump, total pressures of the pump inlet and outlet are obtained from the numerical model. The inlet and outlet of the propulsion pump are presented in Fig. 3. Section 1-1 presents the inlet and section 2-2 the outlet. The hydraulic performance of the propulsion pump, which is described by the head $H$, the shaft power $N$ and the efficiency $\eta$, is calculated according to Eqs. (1) (4).

$$
\begin{aligned}
& P_{\text {total }}=P_{2 \text { total }}-P_{1 \text { total }} \\
& H=\frac{P_{\text {total }}}{\rho g} \\
& N=\frac{T \times n}{9550} \\
& \eta=\frac{\rho g Q H}{N}
\end{aligned}
$$




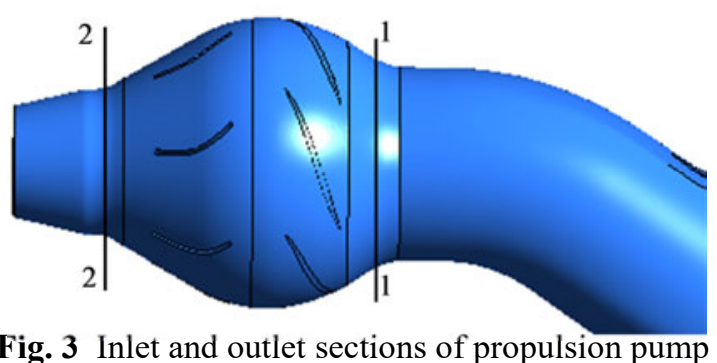

where $P_{\text {total }}$ is the total pressure $(\mathrm{Pa}), T$ is the torque on the impeller $(\mathrm{N} \cdot \mathrm{m}), n$ is the angular velocity of the impeller ( $\mathrm{r} / \mathrm{min}), N$ is the shaft power $(\mathrm{kW})$.

Fig. 4 shows hydraulic performance curves of the propulsion pump. The $Q-H$ curve has a positive slope area, from $0.375 Q_{\mathrm{BEP}}$ to $0.5 Q_{\mathrm{BEP}}$. $Q_{\mathrm{BEP}}$ is the flow rate based on the best efficiency point (BEP) condition. According to the literature [14], the rotating stall in the pump occurs in the positive slope area. Hence the stall occurs when the flow rate is between $0.375 Q_{\mathrm{BEP}}$ and $0.5 Q_{\mathrm{BEP}} \mathrm{H} / H_{\mathrm{BEP}}$ has a slight downward trend while the flow rate changes from $0.5 Q_{\mathrm{BEP}}$ to $0.75 Q_{\mathrm{BEP}}$.

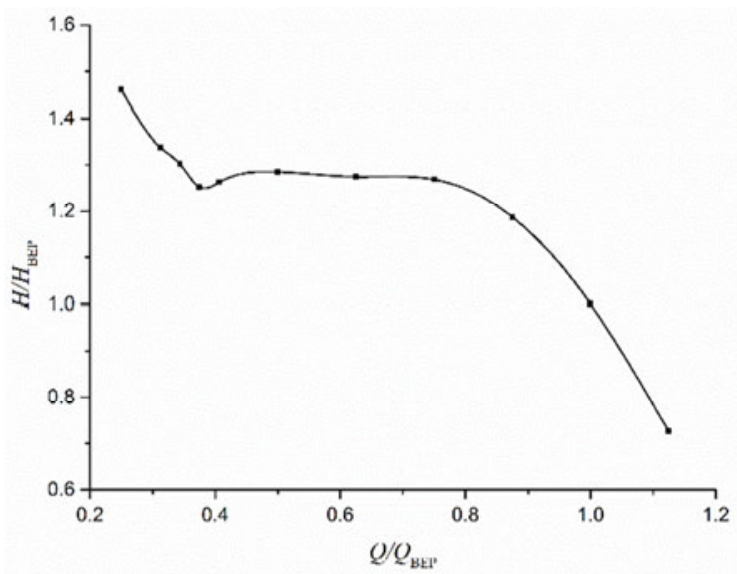

(a) $Q-H$ curve

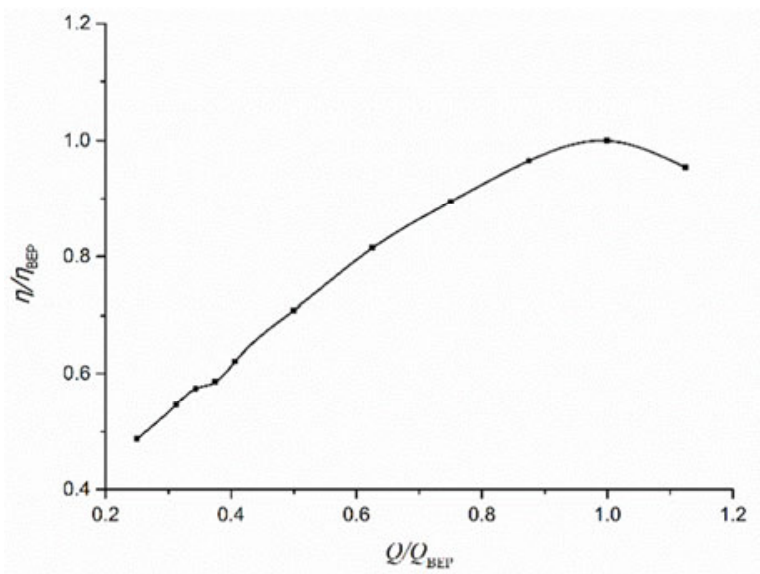

(b) $Q-\eta$ curve

Fig. 4 Hydraulic performance curves of propulsion pump

\section{Experimental verification}

A test facility is built which consists of two closed-loop circuits with a total length of 15 $\mathrm{m}$, as shown in Fig. 5. One circuit is used to provide navigation speed for the propulsion pumping system. The other is applied to measuring performance of the pumping system. The propulsion pumping system consists of a propulsion pump, a guide vane and an inlet passage, as shown in Fig. 6. The propulsion pump with six impeller blades and a stator bowl with seven stator vanes is built into the system. It is a scale model of a waterjet pump used for ship propulsion. The pump is driven by a DC electric motor via a system. A frequency controller is used to regulate the shaft speed. The flow rate of the pump is measured by an electromagnetic flow meter with an absolute accuracy of $\pm 0.5 \%$. The head of the propulsion is measured with an uncertainty of $\pm 0.1 \%$.

Fig. 7 presents a comparison of the hydraulic performance between the test results and the numerical results. It can be noted that the efficiency performance of the numerical results is in good agreement with the experimental results. The numerical values of the head performance are higher than the experimental values by $3.2 \%$ at the $0.5 Q_{\mathrm{BEP}}$ flow rate. The 
C. Xia, L. Cheng, C. Luo, W. Jiao, D. Zhang
Hydraulic Characteristics and Measurement of Rotating Stall Suppression in a Waterjet Propulsion System

deviation of the head performance results from the fixed navigation speed used in the numerical simulation as the inlet boundary condition, which fluctuates in the experiment due to the interaction effect of the two closed-loop circuits.

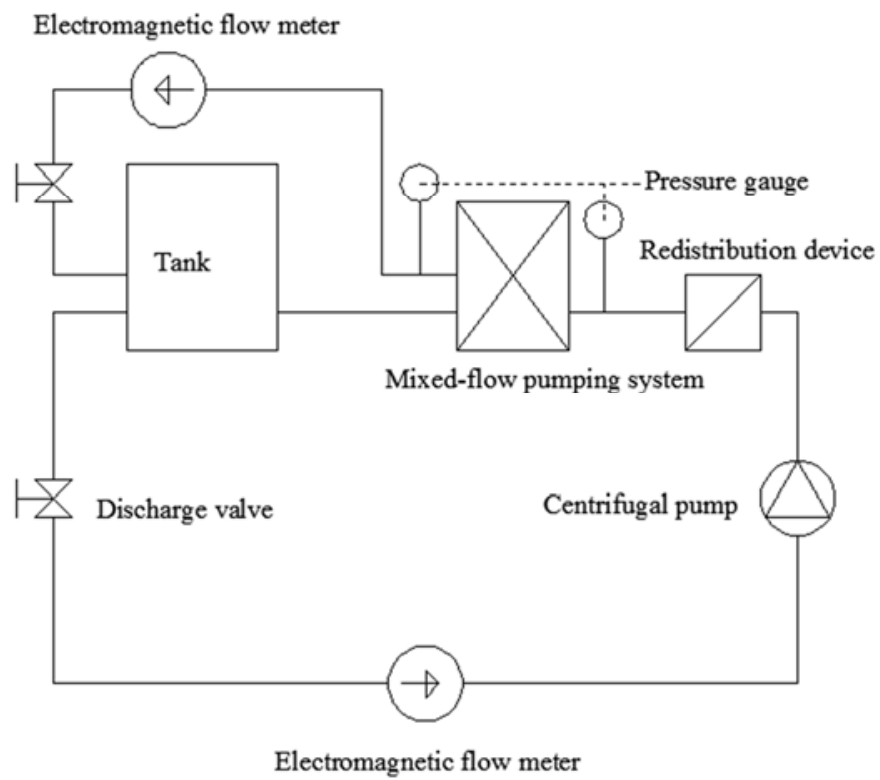

Fig. 5 Experimental facility

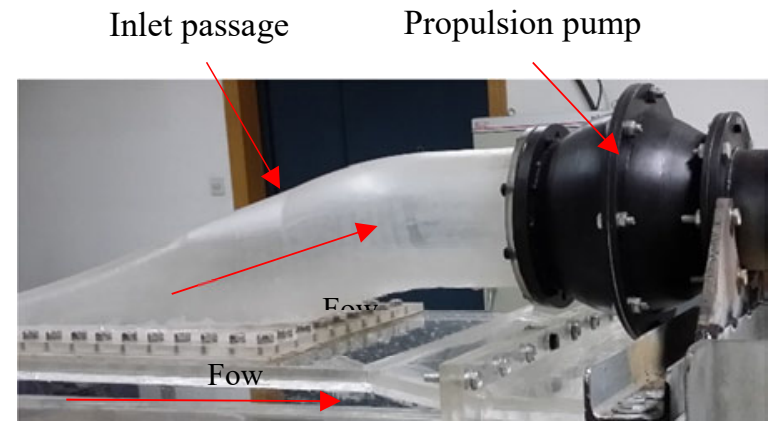

Fig. 6 Propulsion pumping system

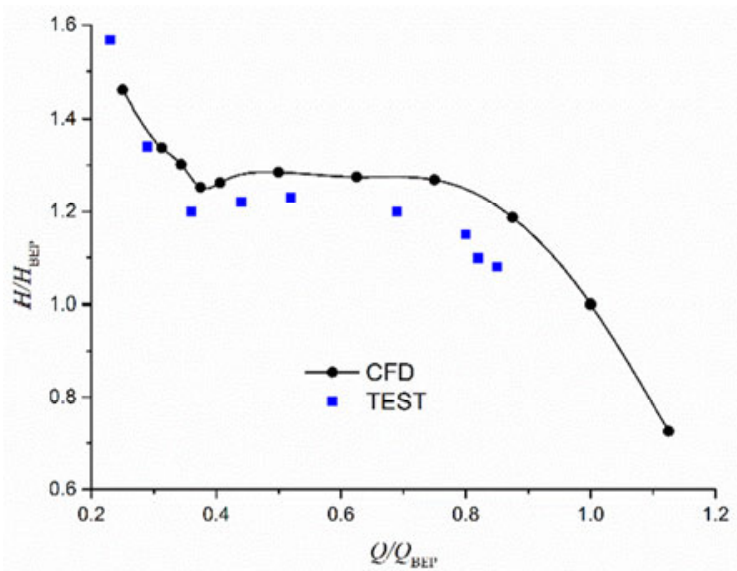

(a) $Q-H$ curve

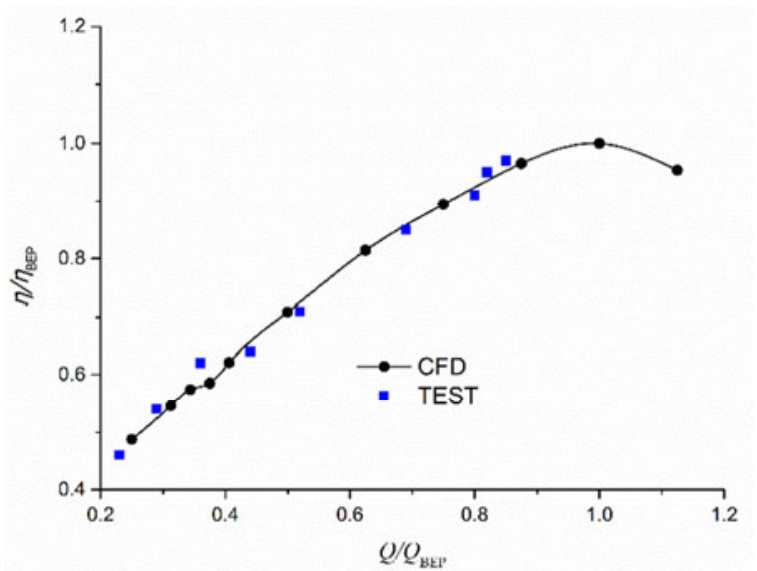

(b) $Q-\eta$ curve

Fig.7 Comparison of numerical and test results 


\section{Flow characteristics}

\subsection{Flow pattern in the impeller}

In order to study the flow characteristics of the impeller in the rotating stall condition, six special conditions of the waterjet propulsion system are selected to analyse the flow pattern in the impeller, as shown in Fig. 8. These special conditions include the low flow rate condition $0.25 Q_{\mathrm{BEP}}$, the BEP flow rate condition $Q_{\mathrm{BEP}}$ and three rotating stall conditions from $0.375 Q_{\mathrm{BEP}}$ to $0.5 Q_{\mathrm{BEP}}$. When the flow rate equals $0.25 Q_{\mathrm{BEP}}$, the separation group is found between every two blades, namely, the flow pattern is unsatisfactory in the low flow rate condition. The area of the separation group between the blades decreases with an increase in the flow rate. When the flow rate increases to $0.438 Q_{\mathrm{BEP}}$, two separation groups vanish, as shown in Fig. 8. The separation groups continue to shrink on the basis of the $0.438 Q_{\mathrm{BEP}}$ at $0.5 Q_{\mathrm{BEP}}$ condition. The separation groups disappear in the BEP condition.

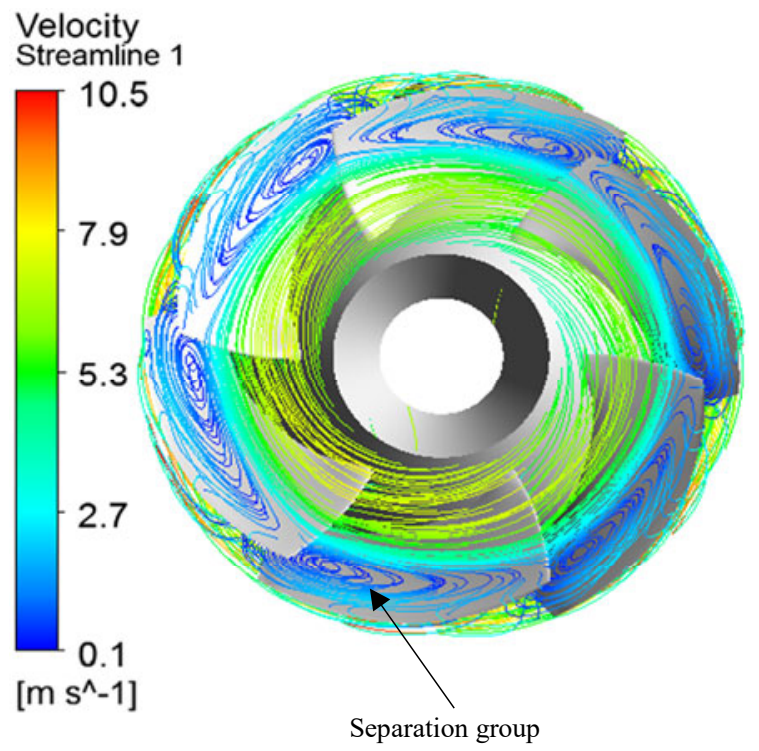

(a) $0.25 Q_{\mathrm{BEP}}$

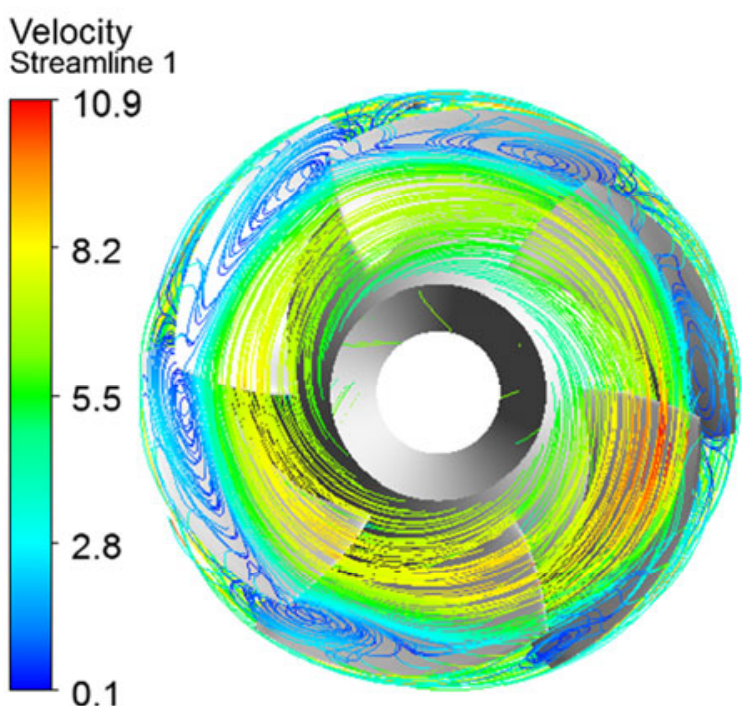

$\left[\mathrm{m} \mathrm{s}^{\wedge}-1\right]$

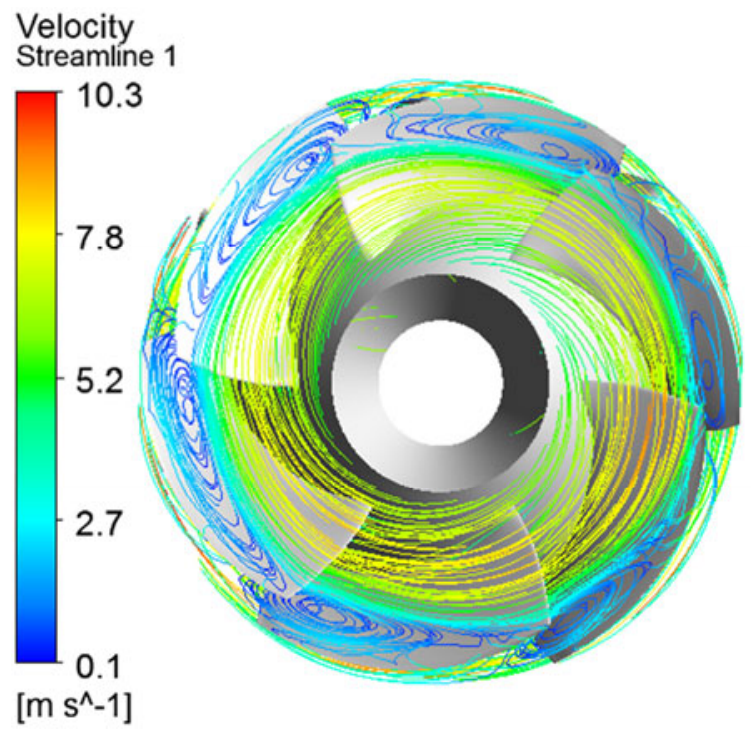

(b) $0.375 Q_{\text {BEP }}$

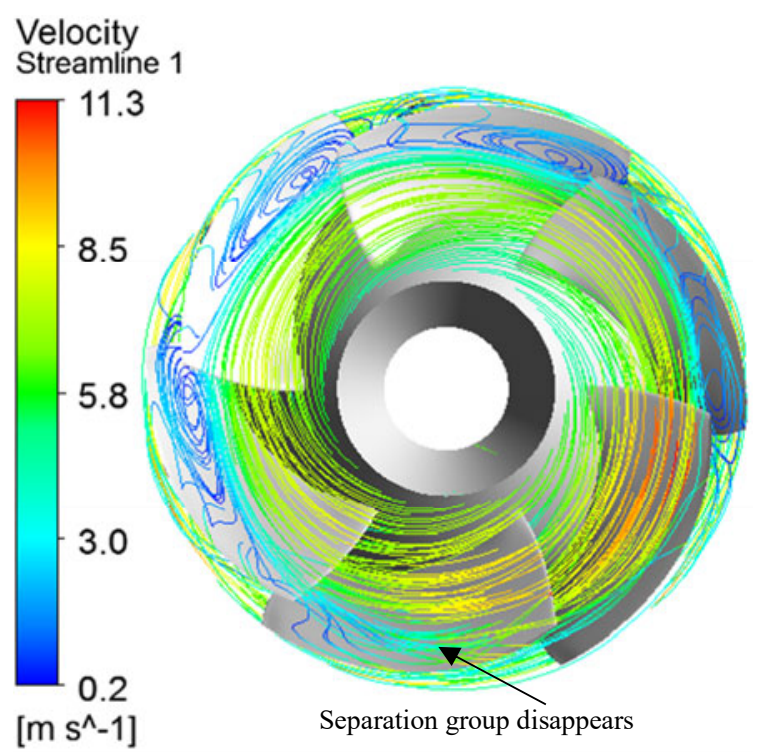

(d) $0.438 Q_{\text {BEP }}$

(c) $0.406 Q_{\mathrm{BEP}}$ 
C. Xia, L. Cheng, C. Luo, W. Jiao, D. Zhang

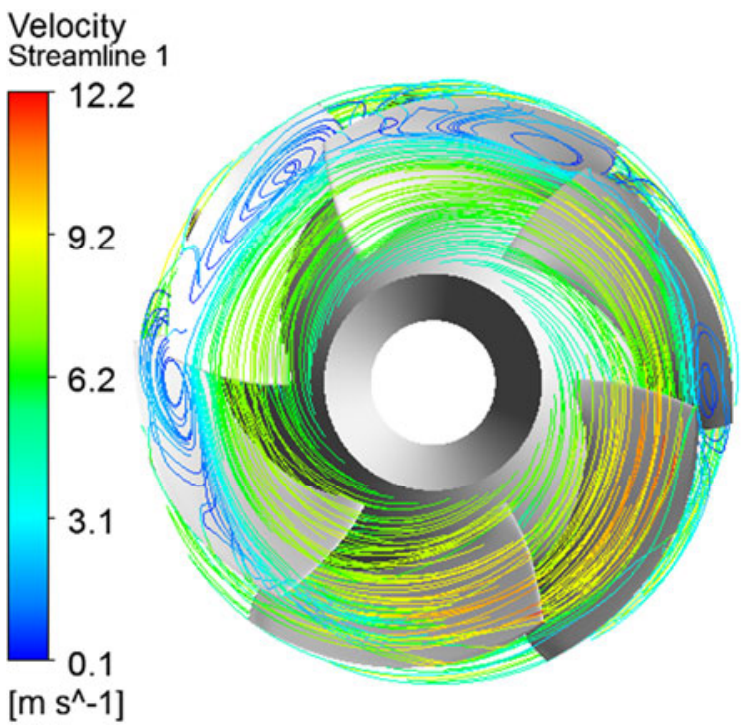

(e) $0.5 Q_{\mathrm{BEP}}$
Hydraulic Characteristics and Measurement of Rotating Stall Suppression in a Waterjet Propulsion System

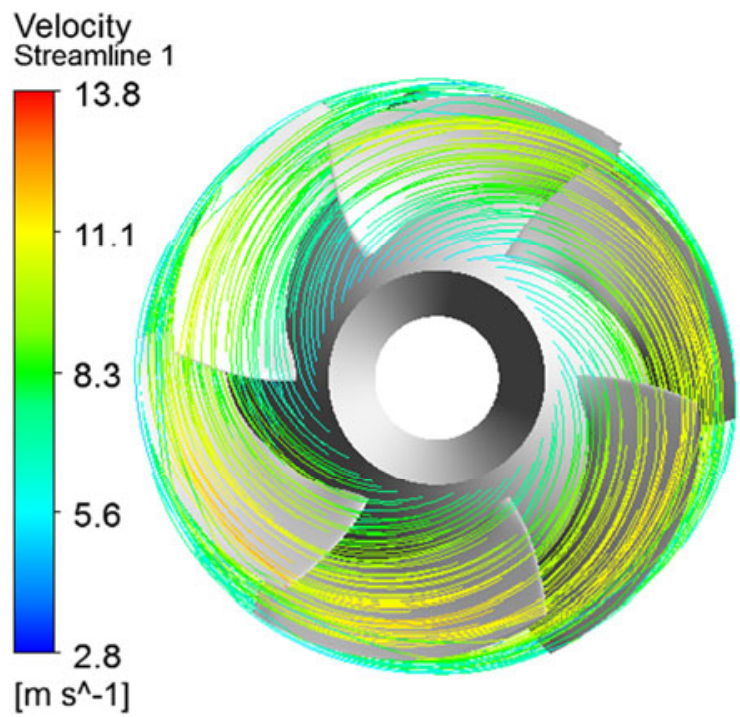

(f) $Q_{\mathrm{BEP}}$

Fig. 8 Front views of streamline in the impeller in different flow rate conditions

\subsection{Flow pattern in the guide vane}

Fig. 9 shows the flow pattern in the guide vane in different conditions. When the flow rate is $0.25 Q_{\mathrm{BEP}}, 0.375 Q_{\mathrm{BEP}}$ and $0.406 Q_{\mathrm{BEP}}$, there are obvious separation groups in each bladeto-blade passage of the guide vane. The guide vane cannot adjust the flow well in the rotating stall condition because the flow direction deflects seriously from the design condition at the impeller's outlet. When the flow rate is $0.5 Q_{\mathrm{BEP}}$, there is a blade-to-blade passage with no obvious separation group. The flow pattern in the guide vane is highly satisfactory, and there is no separation group in the impeller in the $Q_{\mathrm{BEP}}$ condition.

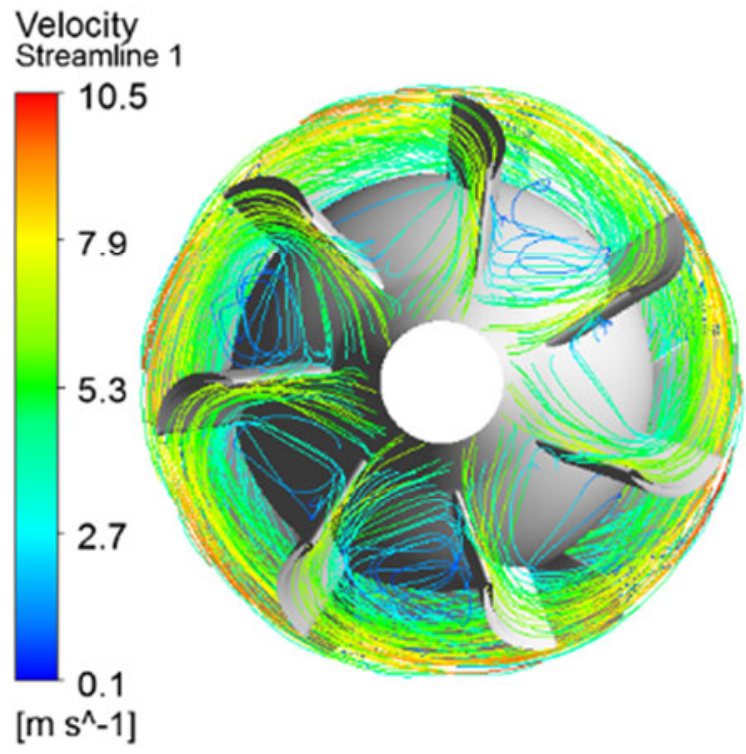

(a) $0.25 Q_{\mathrm{BEP}}$

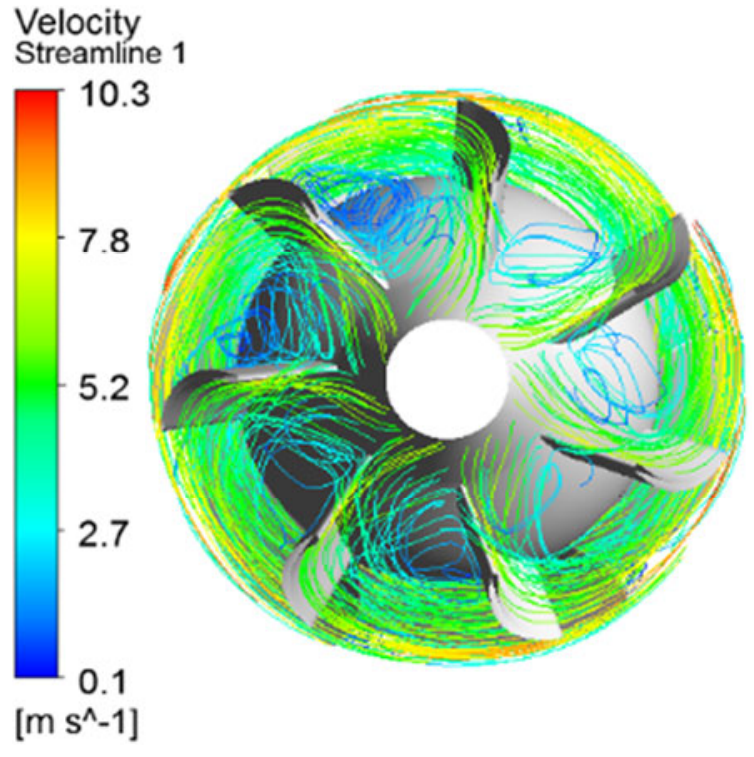

(b) $0.375 Q_{\mathrm{BEP}}$ 


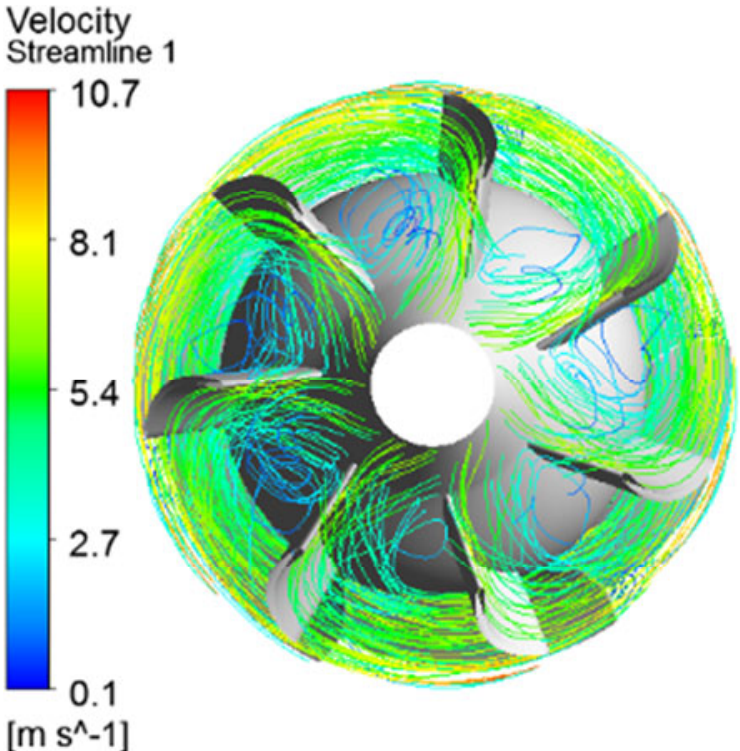

(c) $0.406 Q_{\mathrm{BEP}}$

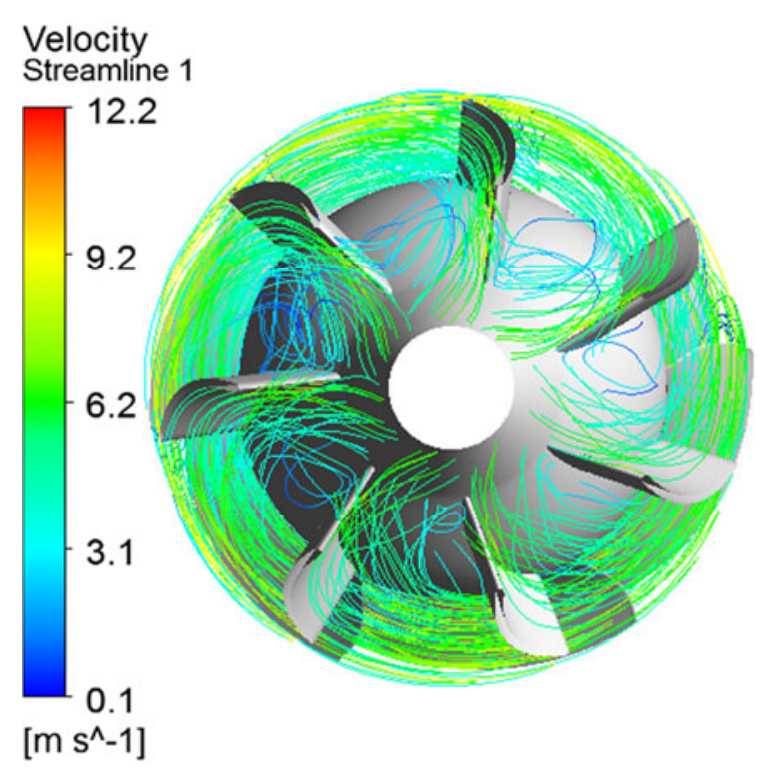

(e) $0.5 Q_{\mathrm{BEP}}$

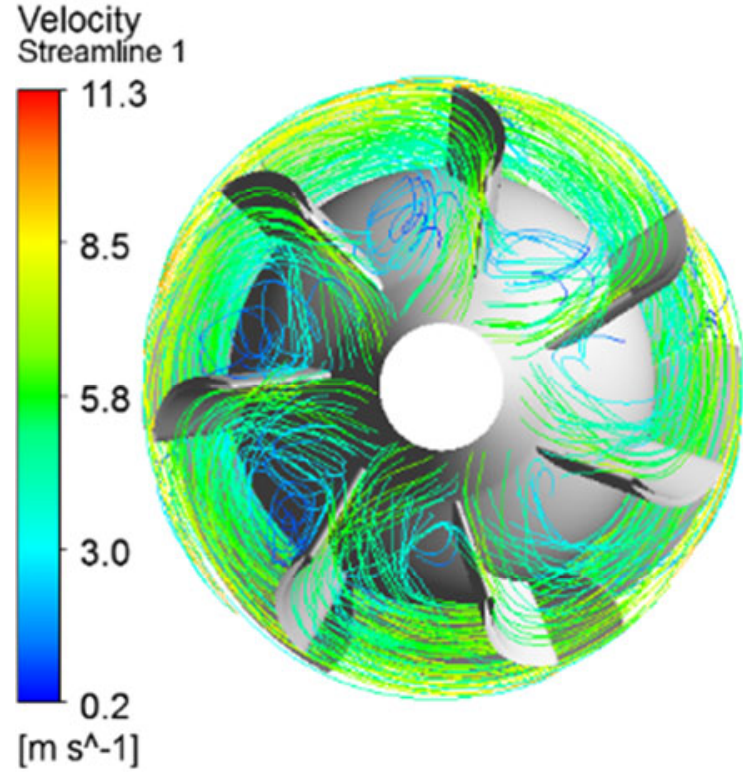

(d) $0.438 Q_{\text {BEP }}$

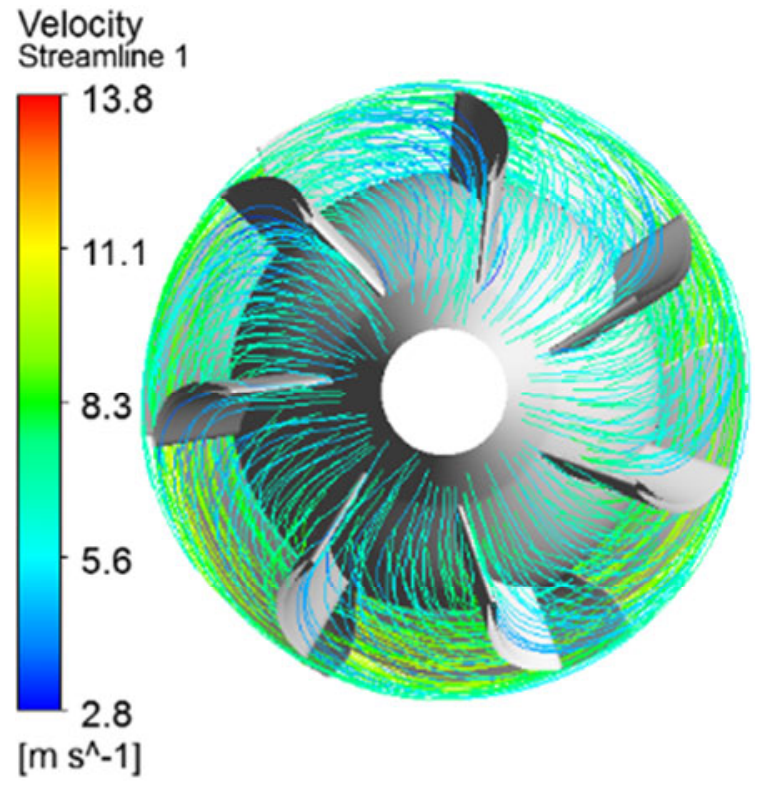

(f) $Q_{\text {BEP }}$

Fig. 9 Streamline in the guide vane in each condition

\subsection{Vector distribution in different span values}

Span is defined as the dimensionless distance (between 0 and 1) from the hub to the shroud, as shown in Fig. 10. Fig. 11 shows the velocity vector around the airfoil in the $0.406 Q_{\mathrm{BEP}}$ condition, which is a rotating stall condition. With an increase in the span value, the area of separation groups decreases by comparing the velocity vector distribution in different spans. The separation group disappears in the span $=0.4$ section, which means that rotating stall occurs in the region near the shroud in the propulsion pump. 
C. Xia, L. Cheng, C. Luo, W. Jiao, D. Zhang
Hydraulic Characteristics and Measurement of Rotating Stall Suppression in a Waterjet Propulsion System

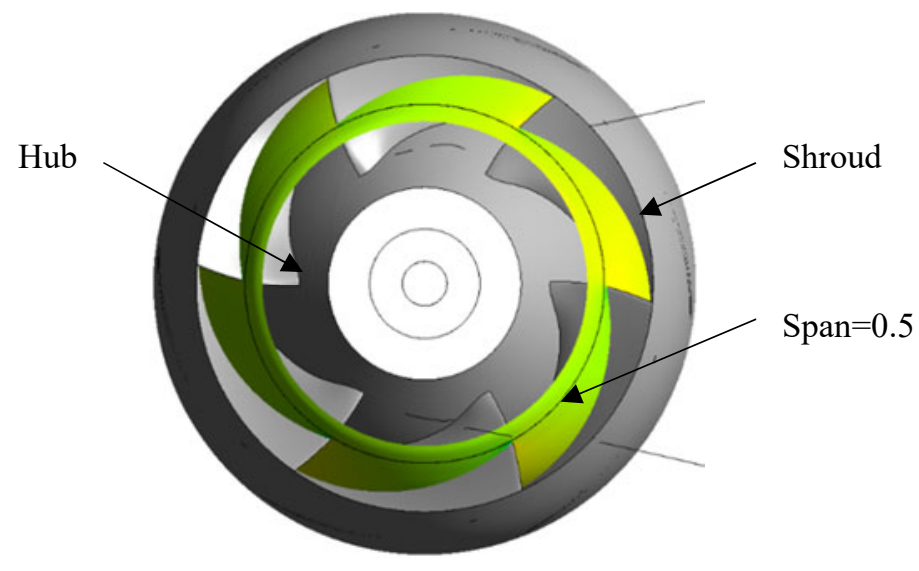

Fig. 10 General view of span

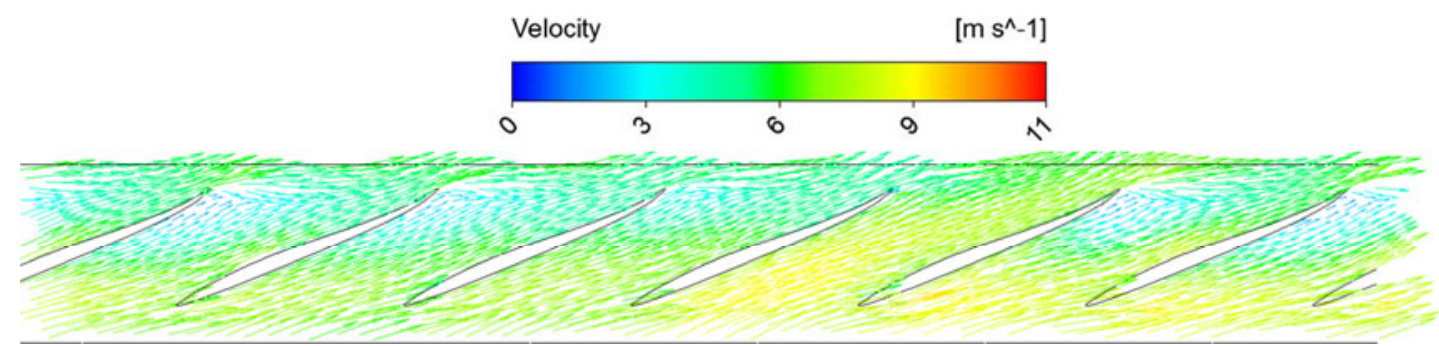

(a) $\mathrm{Span}=0.4$

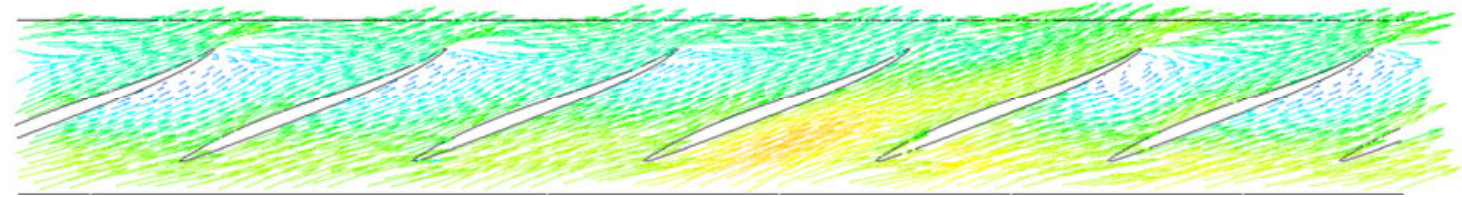

(b) $\mathrm{Span}=0.5$

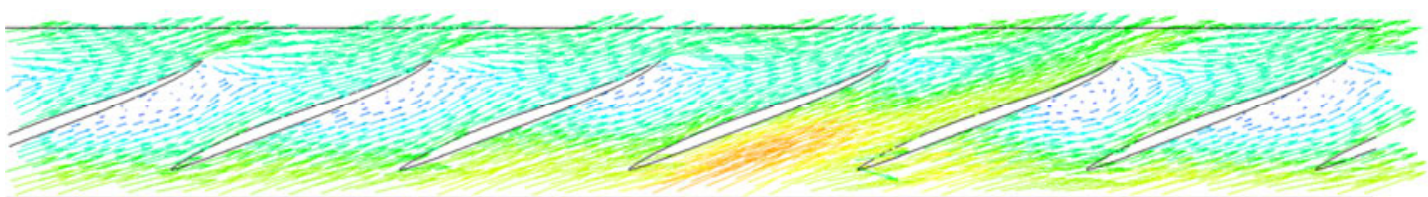

(c) Span $=0.6$

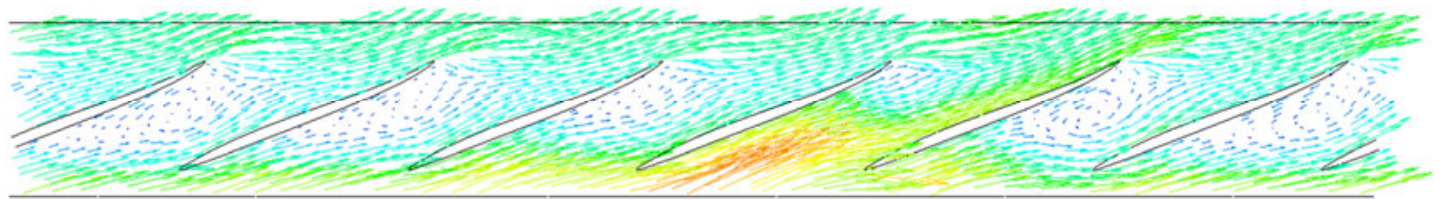

(d) $\operatorname{Span}=0.7$

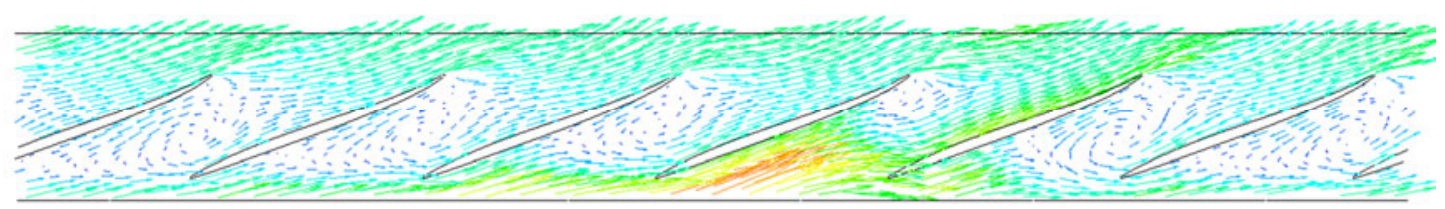

(e) $\mathrm{Span}=0.8$

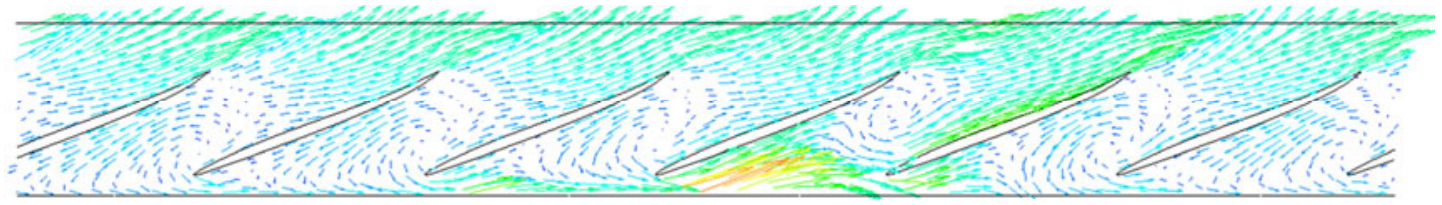

(f) $\mathrm{Span}=0.9$

Fig. 11 Velocity vector around airfoil at $0.406 Q_{\mathrm{BEP}}$ 


\section{Stall suppression}

\subsection{Separator measures}

The flow in the inlet of the pump could be affected by many factors, such as the shape of the inlet passage, pump rotational speed and navigation speed. The unsatisfactory inlet flow pattern could result in the rotating stall in the low flow rate condition. In this study, several separators were set in the outlet of the inlet passage to improve the inlet flow pattern of the pump, as shown in Fig. 12. The main parameters of the separator are as follows: thickness of separator $\left(P_{\mathrm{B}}\right)$, length $\left(P_{\mathrm{L}}\right)$, distance from the rotational axis $\left(P_{\mathrm{V}}\right)$, location $\left(P_{\mathrm{X}}\right)$ and number of separators $\left(P_{\mathrm{N}}\right)$.

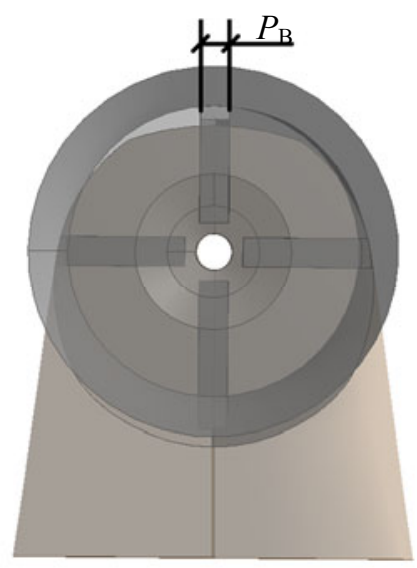

(a) side view

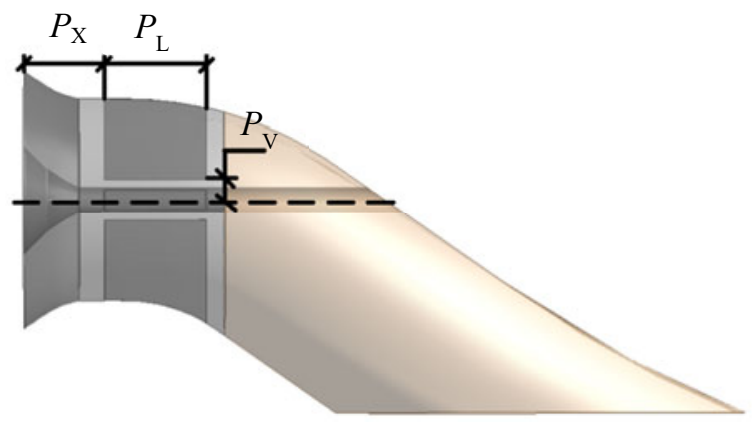

(b) front view

Fig. 12 Separator

\subsection{Research schemes}

Twelve schemes are designed to analyze the influence of different separator parameters on the rotating stall suppression as shown in Table 2. Schemes 1-3 mainly study the influence on the flow pattern by changing the height of the separators. Schemes 4-5 mainly study the influence on the flow pattern by changing the thickness of the separators. Schemes 6-8 mainly study the influence on the flow pattern by changing the length of the separators. Schemes 910 mainly study the influence on the flow pattern by changing the location of the separators. Schemes 11-12 mainly study the influence on the flow pattern by changing the number of separators.

Table 2 Research schemes of separator

\begin{tabular}{cccccc}
\hline Scheme & $\begin{array}{c}\text { Length } \\
\left(P_{\mathrm{L}}\right)\end{array}$ & $\begin{array}{c}\text { Height } \\
\left(P_{\mathrm{V}}\right)\end{array}$ & $\begin{array}{c}\text { Location } \\
\left(P_{\mathrm{X}}\right)\end{array}$ & $\begin{array}{c}\text { Thickness } \\
\left(P_{\mathrm{B}}\right)\end{array}$ & $\begin{array}{c}\text { Number } \\
\left(P_{\mathrm{N}}\right)\end{array}$ \\
\hline 1 & $0.5 D_{0}$ & $0.1 D_{0}$ & $0.4 D_{0}$ & $0.05 D_{0}$ & 4 \\
2 & $0.5 D_{0}$ & $0.25 D_{0}$ & $0.4 D_{0}$ & $0.05 D_{0}$ & 4 \\
3 & $0.5 D_{0}$ & $0.4 D_{0}$ & $0.4 D_{0}$ & $0.05 D_{0}$ & 4 \\
4 & $0.5 D_{0}$ & $0.1 D_{0}$ & $0.4 D_{0}$ & $0.1 D_{0}$ & 4 \\
5 & $0.5 D_{0}$ & $0.1 D_{0}$ & $0.4 D_{0}$ & $0.025 D_{0}$ & 4 \\
6 & $0.1 D_{0}$ & $0.1 D_{0}$ & $0.4 D_{0}$ & $0.025 D_{0}$ & 4 \\
\hline
\end{tabular}




\begin{tabular}{cccccc}
\hline Scheme & $\begin{array}{c}\text { Length } \\
\left(P_{\mathrm{L}}\right)\end{array}$ & $\begin{array}{c}\text { Height } \\
\left(P_{\mathrm{V}}\right)\end{array}$ & $\begin{array}{c}\text { Location } \\
\left(P_{\mathrm{X}}\right)\end{array}$ & $\begin{array}{c}\text { Thickness } \\
\left(P_{\mathrm{B}}\right)\end{array}$ & $\begin{array}{c}\text { Number } \\
\left(P_{\mathrm{N}}\right)\end{array}$ \\
\hline 7 & $0.3 D_{0}$ & $0.1 D_{0}$ & $0.4 D_{0}$ & $0.025 D_{0}$ & 4 \\
8 & $0.7 D_{0}$ & $0.1 D_{0}$ & $0.4 D_{0}$ & $0.025 D_{0}$ & 4 \\
9 & $0.5 D_{0}$ & $0.1 D_{0}$ & $0.2 D_{0}$ & $0.025 D_{0}$ & 4 \\
10 & $0.5 D_{0}$ & $0.1 D_{0}$ & $0.05 D_{0}$ & $0.025 D_{0}$ & 4 \\
11 & $0.5 D_{0}$ & $0.1 D_{0}$ & $0.4 D_{0}$ & $0.025 D_{0}$ & 2 \\
12 & $0.5 D_{0}$ & $0.1 D_{0}$ & $0.4 D_{0}$ & $0.025 D_{0}$ & 6 \\
\hline
\end{tabular}

6.3 Influence of the separator height on stall

Fig. 13 presents the hydraulic performance of the separator schemes with different height parameters. In comparison to original schemes without separators, the head of the separator decreases significantly in the flow rate range from $0.406 Q_{\mathrm{BEP}}$ to $0.875 Q_{\mathrm{BEP}}$ and increases slightly at $0.375 Q_{\mathrm{BEP}}$, which reduces the positive slope area. This means that rotating stall is suppressed by setting the separators. Besides, there is a small difference in the positive slope area between three separator height schemes. And the efficiency of the propulsion pump system decreases with an increase in the height parameter of the separator. For this reason, the recommend height parameter of the separator is $0.1 D_{0}$.

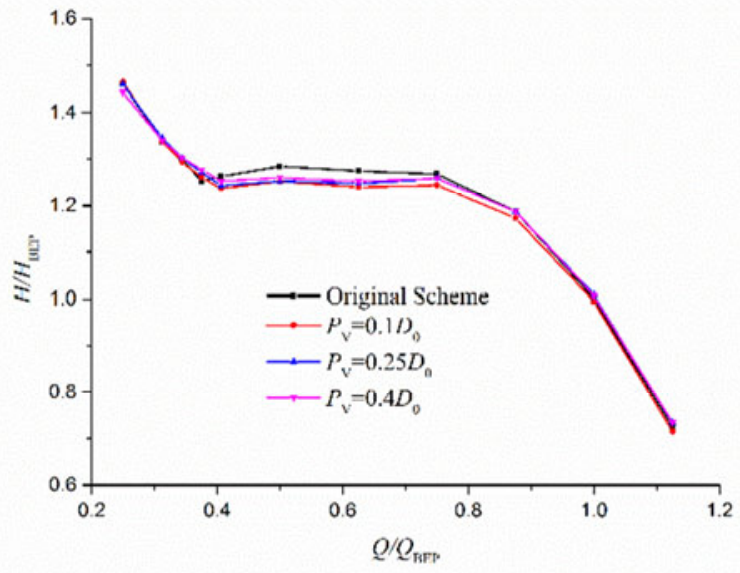

(a) $Q-H$ curve

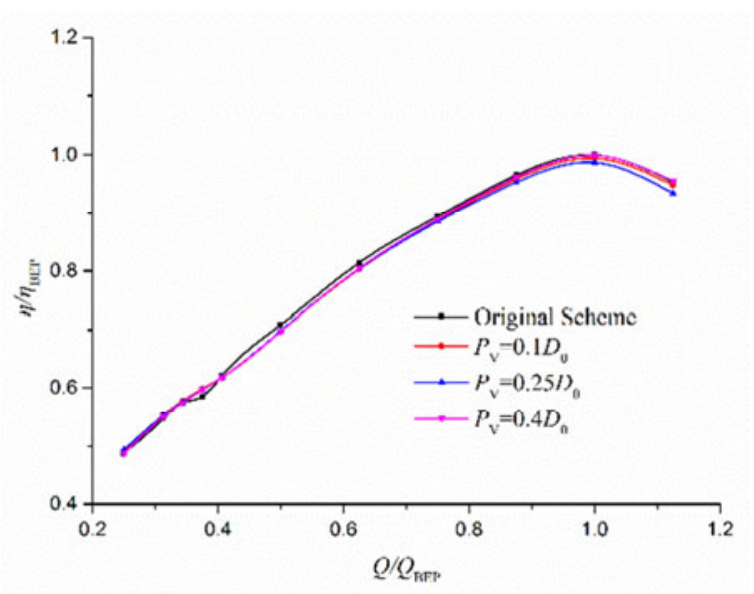

(b) $Q-\eta$ curve

Fig. 13 Hydraulic performance of separator schemes with different heights

\subsection{Influence of the separator thickness on stall}

Fig. 14 shows the hydraulic performance of separator schemes with different thickness. On the basis of scheme 1, the thickness of the separator is changed and other separator parameters are the same. According to the hydraulic performance curve of the separator scheme with different thicknesses, the overall hydraulic performance curve is nearly the same except for the decreasing head. The thickness of the separator has little influence on the efficiency. But when the flow rate increases especially when the flow rate is greater than $\mathrm{Q}_{\mathrm{BEP}}$, the thickness of the separator has a strong effect on the efficiency. As the thickness of the separator increases, the efficiency decreases. For this reason, the recommended thickness parameter of the separator is $0.025 D_{0}$. 


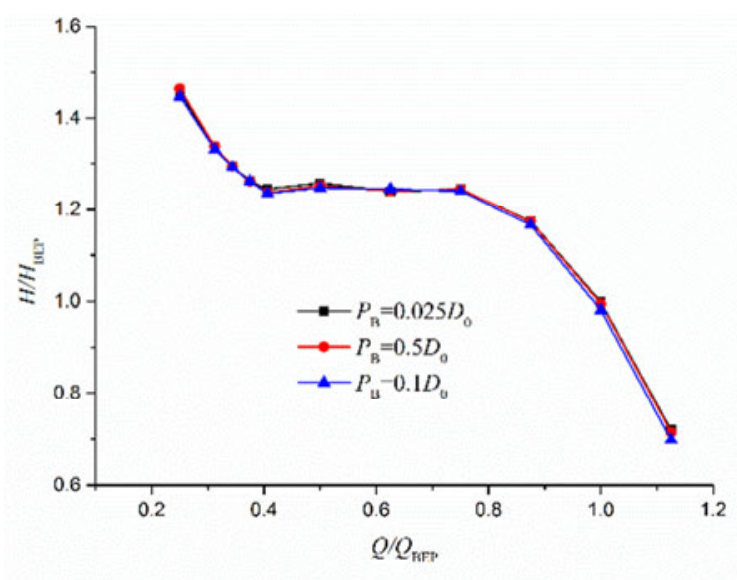

(a) $Q-H$ curve

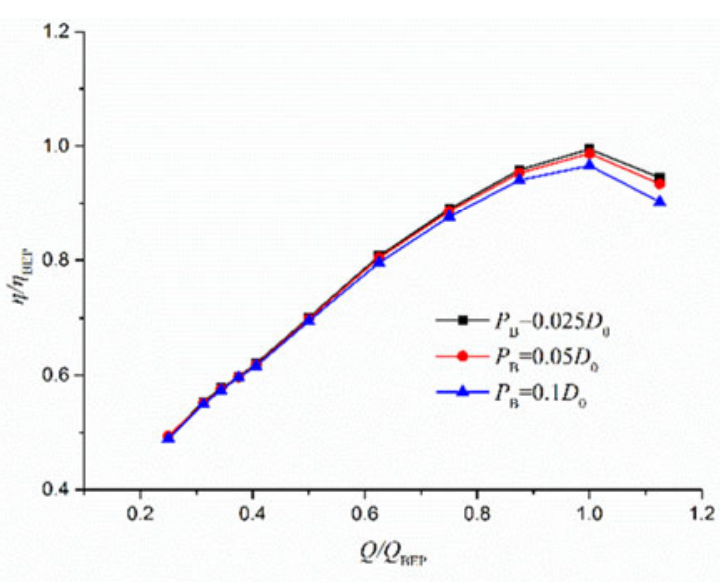

(b) $Q-\eta$ curve

Fig. 14 Hydraulic performance curve of separator schemes with different thicknesses

\subsection{Influence of the separator length on stall}

Fig. 15 presents the hydraulic performance of separator schemes with different lengths. On the basis of scheme 5, the length of the separator is changed and other separator parameters are the same. When the flow rate is between $0.6 Q_{\mathrm{BEP}}$ and $0.8 Q_{\mathrm{BEP}}$, the length of the separator has an obvious influence on the $Q-H$ curve. When the length of the separator is $0.1 D_{0}$ and $0.3 D_{0}$, there is little difference between their $Q-H$ curves. When the length of the separator increases to $0.5 D_{0}$ and $0.7 D_{0}$, the head decreases obviously at the flow rate range between $0.6 Q_{\mathrm{BEP}}$ and $0.8 Q_{\mathrm{BEP}}$. The positive slope area in the $Q-H$ curve disappears. Additionally, the efficiency decreases with an increase in the length of the separator. For this reason, the recommended length parameter of the separator is $0.5 D_{0}$.

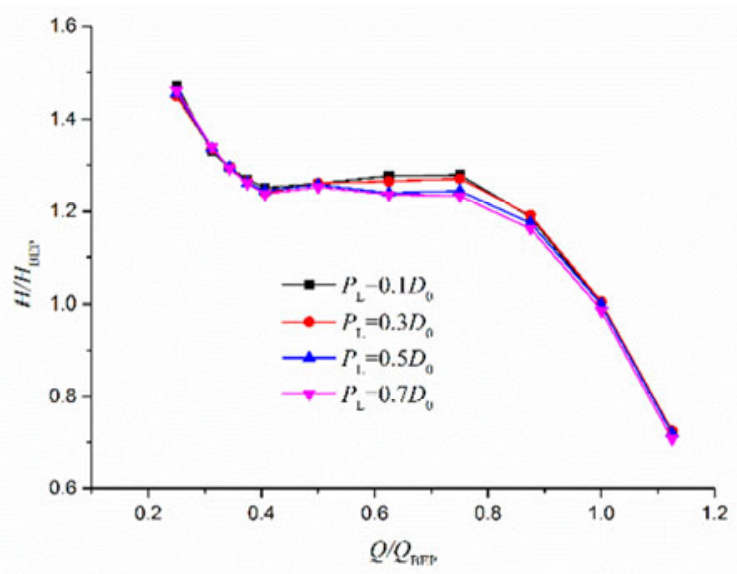

(a) $Q-H$ curve

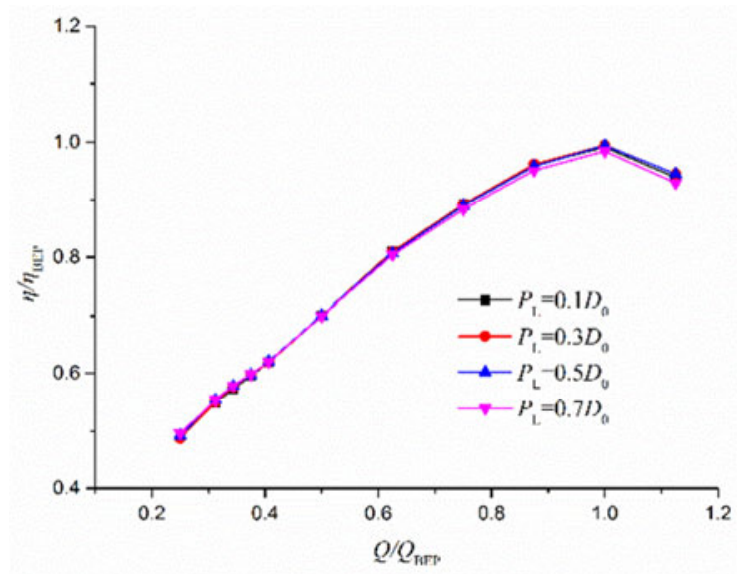

(b) $Q-\eta$ curve

Fig. 15 Hydraulic performance curve of separator schemes with different lengths

\subsection{Influence of the separator location on stall}

Fig. 16 presents the hydraulic performance of separator schemes with different location. When the flow rate is between $0.5 Q_{\mathrm{BEP}}$ and $0.8 Q_{\mathrm{BEP}}$, location has a great influence on the $Q-H$ curve. With a decrease in the $P_{\mathrm{X}}$ value, the separator is closer to the impeller and the $Q-H$ curve is higher when the flow rate is between $0.5 Q_{\mathrm{BEP}}$ and $0.8 Q_{\mathrm{BEP}}$. Namely, the positive slope zone increases. The separator location has little influence on the efficiency. Hence, scheme 5 is still the best, the recommended location parameter of the separator is $0.4 D_{0}$. 
C. Xia, L. Cheng, C. Luo, W. Jiao, D. Zhang

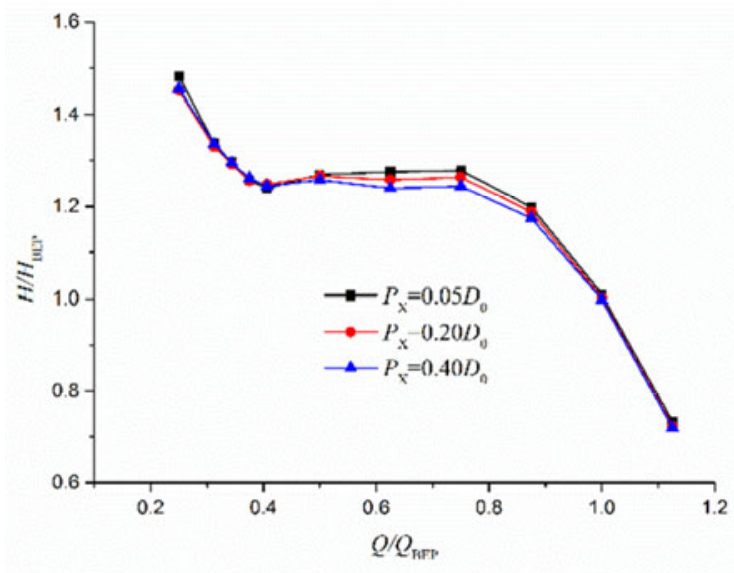

(a) $Q-H$ curve
Hydraulic Characteristics and Measurement of Rotating Stall Suppression in a Waterjet Propulsion System

Fig. 16 Hydraulic performance curve of separator schemes with different locations

\subsection{Influence of the separator number on stall}

On the basis of scheme 5, the number of separators is changed and other separator parameters are the same. Fig. 17 presents the hydraulic performance of separator schemes with different numbers.

When the number of separators is 4 and 6 , the $Q-H$ curve does not change significantly. However, when the number of separators is 2, there is an obvious positive slope area on the $Q-H$ curve. From the $Q-\eta$ curve, it is found that the higher the number of separators, the lower the efficiency. Hence, scheme 5 is the best, the recommended number of separators is 4 .

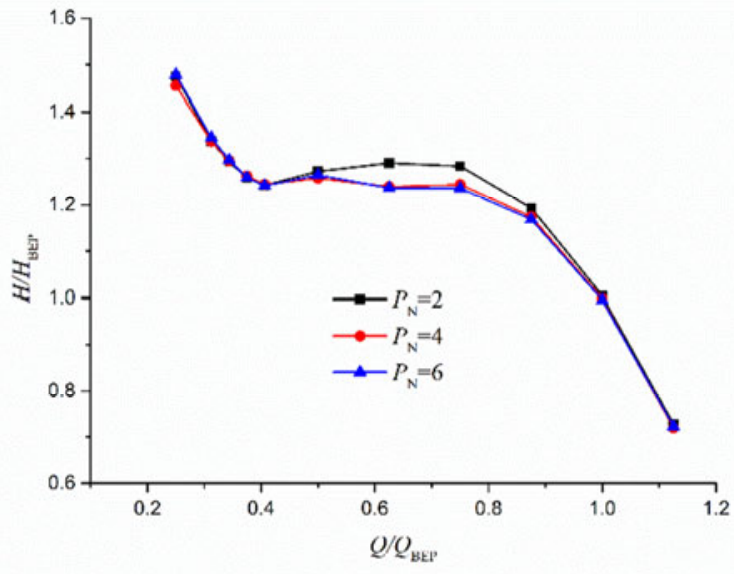

(a) $Q-H$ curve

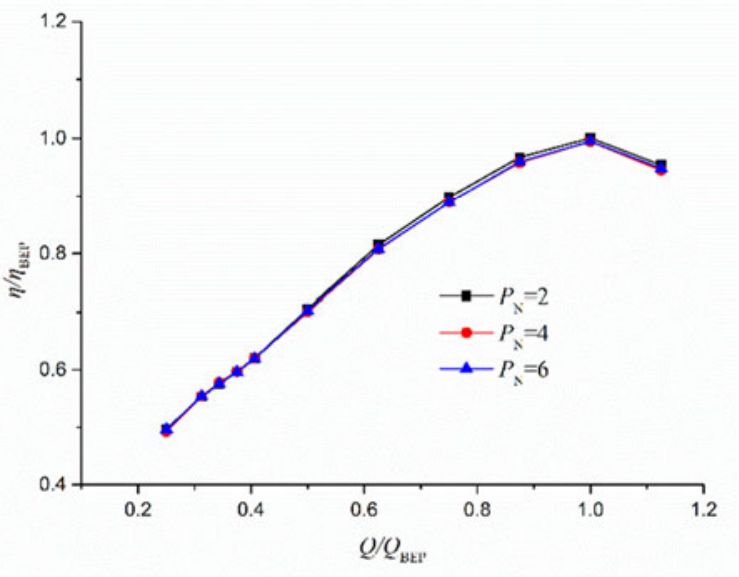

(b) $Q-\eta$ curve

Fig. 17 Hydraulic performance curve of separator schemes with different numbers

\section{Conclusion}

A complete water jet propulsion system including a passage, a propulsion pump and a nozzle is established. This paper analyzes the rotating stall at a low flow rate and suppresses it with separators. The conclusions are as follows:

An obvious rotating stall zone is found on the external characteristic curve at a low flow rate condition. A large scale flow separation region occurs in the propulsion pump. The flow separation around the blade is worse when it is nearer to the rim, which also occurs more easily when the flow rate is lower. 
The flow pattern near the inlet of the propulsion pump and the velocity distribution in the passage are improved when a separator is installed. The rotating stall of a propulsion pump system is significantly controlled by setting separators at the outlet of the inlet passage. The height and thickness parameters of separators have a little influence on the rotating stall suppression. However, the efficiency of the propulsion pump system decreases with an increase in height and thickness. The length, location and number of separators have a significant influence on the result of the rotating stall suppression though they affect slightly the efficiency of the propulsion pump system. The recommend parameters of separators are $0.5 D_{0}$ (length), $0.1 D_{0}$ (height), $0.4 D_{0}$ (location), $0.025 D_{0}$ (thickness), 4 (number of separators).

\section{Acknowledgments}

This work is supported by the National Natural Science Foundation of China (Grant No. 51779214), the Priority Academic Program Development of Jiangsu Higher Education Institutions (PDPA), Jiangsu Province Science Foundation for Youth (Grant No. BK20170507), the Young Academic Leaders of Qinglan Project in Jiangsu Province, Six Talent Peaks Project in Jiangsu Province, Key Project of Water Resources Technology in Jiangsu Province (Grant No. 2016035) and Natural Science Foundation of Jiangsu Higher Education Institutions (Grant No. 17KJD580003).

\section{Nomenclature}

$\begin{array}{ll}L & \text { Length } \\ t & \text { Time } \\ P & \text { Pressure } \\ v & \text { Velocity } \\ N & \text { Power } \\ H & \text { Head } \\ g & \text { Acceleration of gravity } \\ T & \text { Torque } \\ \eta & \text { Efficiency } \\ \rho & \text { Density } \\ Q & \text { Flow rate } \\ \omega & \text { Angular velocity } \\ D & \text { Impeller diameter }\end{array}$

\section{REFERENCES}

[1] W Bulten N, van Esch B. Review of thrust prediction method based on momentum balance for ducted propellers and waterjets. ASME 2005 Fluids Engineering Division Summer Meeting. American Society of Mechanical Engineers, 2005: 1621-1629. https://doi.org/10.1115/FEDSM2005-77209

[2] Faltinsen O M. Hydrodynamics of high-speed marine vehicles. Cambridge: Cambridge university press, 2005. http://dx.doi.org/10.1017/CBO9780511546068

[3] Motte R, Calvert S. Operational Considerations and Constraints in Ship-based Weather Routing Procedures, The Journal of Navigation, 1998, 41(3): 417 433. https://doi.org/10.1017/S0373463300014909

[4] Lin H B. Commentary and improvement on the approximate formulas of ship's speed loss due to weather, Ship Engineering.1988 (01):13-17+1.

[5] Liu F. Study on the ship's loss-speed in wind and waves. Journal of Dalian Marine College. 1992.4(18): 347-351. 
C. Xia, L. Cheng, C. Luo, W. Jiao, D. Zhang
Hydraulic Characteristics and Measurement of Rotating Stall Suppression in a Waterjet Propulsion System

[6] He H M, Dong G X, Jiang Y X. Approximate estimation for ship speed loss in waves. Journal of SSSRI. 2009, 32(02): 6-9

[7] Arpad A Fay. Analysis of separated flows in hydro machines, 6th IASME/WSEAS International Conference on fluid mechanics and aerodynamics (FMA08), Rhodes, Greece, 2008:105-108.

[8] Emmons HW, Pearson C E and Grant HP. Compressor surge and stall propagation, Trans. AsME, 1955, 77: 455 .

[9] Sano T, Yoshida Y, Tsujimoto Y, et al . Numerical study of rotating stall in a pump vaned diffuser. ASME J Fluids Eng. 2002, 124(2): 363-370. https://doi.org/10.1115/1.1459076

[10] Cheng L, Wu L, Liu C. Hydraulic unstable operating region of large scale axial flow pump. Journal of Irrigation and Drainage. 2010, 39 (2): 102-104.

[11] Li S H. Off-design conditions and optimization design of vane pumps. Beijing: Mechanical Industry Press, 2006.

[12] Aertssen G, Speed Loss due to Weather on One Class of Container Ship in the North Atlantic with Reference to Relationship Between Wind and Waves, 14 ${ }^{\text {th }}$ ITTC, Proceeding, 1975, 4: 428.

[13] Cheng L, Qi W J. Rotating stall region of water-jet pump, Transactions of Famena, 2014, 38(2):31-40.

[14] Brennen C E. Hydrodynamics of pumps. Cambridge University Press. 2011. https://doi.org/10.1017/CBO9780511976728

Submitted: $\quad 26.11 .2017$

Accepted: $\quad$ 12.6.2018
Mr. Chenzhi Xia

Prof. Dr. Li Cheng*

Lec. Can Luo

Mr. Weixuan Jiao

Mr. Di Zhang

School of Hydraulic, Energy, and Power

Engineering, Yangzhou University,

Yangzhou, Jiangsu, P.R. China

*Corresponding author,

chengli@yzu.edu.cn 